\title{
Problem relating to framing of hypothesis in legal research
}

Gigi PV*

*Corresponding author:

Dr. Gigi PV Assistant Professor, School of Indian Legal School of Indian Legal Thought, M.G University, Kottayam, Kerala, India

Email: gigisouparnika@gmail.com,_ORCID

\section{Information about the article:}

Received: Jan. 17, 2019

Accepted: Feb. 20, 2019

Published online: Dec. 27, 2019

Publisher

Nepal Health Research Society, Bahundhara -6, Gokarnesowor Municipality, Kathmandu, Nepal eISSN 2382-5545, ISSN 2676-1343 (Print)

(C) The Author(s). 2019

Content licensing: CC BY 4.0

\section{ABSTRACT}

A hypothesis is the starting point of any investigation or inquiry in the process of legal research. For any research to begin, it is always initiated with a problem of inquiry. It is called a tentative statement or generation or assumption or proposition. Whatever it may be, it has to be very clear, simple and definite without any creeping ambiguity therein. The condition attached to it that a hypothesis must be empirically verifiable, testable and comparable with the observed facts regarding a phenomenon or an experience. The formulation of a hypothesis gives direction to arrange the facts. In fact, a hypothesis occupies indispensable portion for any investigation or inquiry. It gives direction in regarding to collection of evidence. It makes observation and experiment possible. It proceeds in a direction to find out answer to the problem saving time, money and energy. Three things are very much essential knowledge, experience and capacity. A researcher has to form hypothesis based on them. We cannot admit anything as valid knowledge until a satisfactory test of the validity of the hypothesis. A researcher cannot satisfy even with results in which he still finds the same occurrence. In a certain place, for example delinquency is found in another area the hypothesis that delinquency in general is due to poverty is false, since other factors than poverty are operative in the production of delinquency among the wealthy. Undoubtedly the test in the first area was correct for that area at the particular time. But delinquency in general cannot be assumed to be due to poverty. So testing of hypothesis is big problem in legal research. If the testing of hypothesis is wrong there ends the research.

Key words

Testing of hypothesis is impossible in legal research. 